KfK 2782

Februar 1979

\title{
Tensile Creep Rupture at Cyclic Load Variation
}

M. Boček

Institut für Material- und Festkörperforschung

\section{Kernforschungszentrum Karlsruhe}



KERNFORSCHUNGSZENTRUM KARLSRUHE

\section{Institut für Material- und Festkörperforschung KfK - 2782}

Tensile Creep Rupture at Cyclic Load Variation

von

M. Bocek

Kernforschungszentrum Karlsruhe G.m.b.H., Karlsruhe 



\section{Abstract}

Assuming the validity of the life fraction rule, the life time is calculated for creep rupture of material subjected to tensile cyclic stress variation. Two cases are considered: a saw - tooth stress-time profile with zero and non-zero holding period. The life times and hence the number of cycles at fracture can be predicted by means of values from the static stress-rupture diagram ( $\left.n, \tau_{0},{ }^{\tau} \max \right)$ and values characterizing the stress cycle $\left(a, v, t_{H}\right)$.

The calculations for zero holding period are compared to experiments performed on the stainless steel type: DIN 1.4970 at $700^{\circ} \mathrm{C}$. Very good agreement is obtained for loading conditions leading to shorter rupture times.

\section{Spannungszyklierung im Zugschwellbereich}

Unter Annahme der Gültigkeit der Summenregel der Lebensanteile wurde die standzeit berechnet für Materialien, die im Zug einer Wechsellastbeanspruchung unterworfen sind. Behandelt wird der Fall von Belastung mit sägezahnförmigem Spannungs-Zeit Verlauf, mit und ohne Haltezeit. Die standzeiten und folglich auch die Bruchlastspielzahlen können vorherbestimmt werden, allein anhand der Kenngrößen statischer Zeitstanddiagramme und des Spannungs-zeit Profils.

Die Rechnungen werden verglichen mit Ergebnissen von Experimenten am Stahl DIN 1.4970. Die Proben wurden Zug-Spannungswechseln ohne Haltezeit bei $700^{\circ} \mathrm{C}$ unterworfen. Die Übereinstimmung ist für kürzere Standzeiten sehr gut. 



\section{Introduction}

The problem of predicting the life time of structures subjected to tensile creep under varying loads has been repeatedly treated. For a review see e.g. the paper of TAIRA [1]. Assuming the validity of the life fraction rule (LFR) recently the time to rupture as well as the stress and temperature at failure have been calculated by the author [2] for several ramp loading conditions. Therefore the results of ramp rupture tests can be predicted solely on the basis of iso-stress rupture experiments without any fitting procedure. As far as the fracture sensitive "structure" of the material is kept unchanged during the test, the agreement between the calculations and the experimental results turned out to be surprisingly good.

This enconraged the author to extend the model on tensile creep fracture for cyclic varying loads. As a special case a saw tooth stress-time profile with different holding periods is treated.

\section{Theoretical}

\subsection{Saw tooth stress-time profile with zero holding period}

The present case is visualized in Fig. 1. The stress-time profile is considered to be composed from two linear (time independent) stress ramps with the stress rates $b_{1}$ and $-b_{1}$.

For a single o-ramp at constant temperature as far as the LFR is obeyed it holds [2]

$$
\int_{\sigma_{0}}^{\gamma_{B}} \frac{d t}{\tau[\sigma(t)]_{T}}=1
$$

Where $\sigma_{0}, \tilde{\sigma}_{B}$ is the "starting" stress and the stress at failure respectively.

Inserting into $\mathrm{Eq}(2.1,1)$ for the life time $\tau$ from experiments [ 3 ]

$$
\tau=\tau_{0}\left(\frac{\sigma_{0}}{\sigma}\right)^{n}
$$


(where $-\frac{1}{n}$ is the solpe in the stress rupture diagram) together with

$\mathrm{b}=\frac{\mathrm{d} \sigma}{\mathrm{d} t}=$ const.

it is

$\tilde{\sigma}_{B}=\left\{\sigma_{0}^{n}\left[b \tau_{0}(n+1)+\sigma_{0}\right]\right\}_{T, b}^{\frac{1}{n+1}}$

Applying in LFR to the present case it holds

$$
\begin{aligned}
& \frac{1}{b_{1}} \int_{\sigma_{0}}^{\sigma \max } \frac{d \sigma}{\tau(\sigma)}-\frac{1}{b_{1}} \int_{\sigma \max }^{\sigma} \frac{d \sigma}{\tau(\sigma)}+\frac{1}{b_{1}} \int_{\sigma_{0}}^{\sigma} \frac{d \sigma}{\tau(\sigma)}-\ldots+\ldots \\
& \int \frac{d \sigma}{\tau(\sigma)} \\
& \sigma_{0}^{\prime} \sigma_{\max }
\end{aligned}
$$

or

$$
M_{E} \int_{\sigma}^{\sigma \max } \frac{d \sigma}{\tau(\sigma)}=b_{1}\left\{1+\left|\frac{1}{b_{1}}\right| \int_{\sigma_{0^{\prime}} \sigma_{\max }^{\sigma}}^{\sigma} \frac{d \sigma}{\tau(\sigma)}\right\}
$$

Where $M_{f}$ is the number of individual loading steps to fracture for the stress at failure $\sigma_{f}$ it is $\sigma_{0} \leq \sigma_{f} \leq \sigma_{\max }$.

It follows for the time to failure

$c_{\tau}=\frac{\delta \cdot M_{f}}{2}+\Delta t$

where $\delta$ is the loading period. 
The term

$\frac{1}{\left|b_{1}\right|} \int_{\sigma^{\prime} \sigma_{\max }^{\sigma}}^{\sigma} \frac{d \sigma}{\tau(\sigma)}$

is the residuum of the serie in Eq (2.1.3). Obviously it holds for $\Delta t$ in $\mathrm{Eq}(2.1 .5)$ that

$\Delta t=\frac{\delta}{2} \frac{\left|\int_{\sigma_{O^{\prime}} \sigma_{\max }}^{\sigma} \frac{d \sigma}{\tau(\sigma)}\right|}{\int_{\sigma_{0}}^{\sigma_{\max }} \frac{d \sigma}{\tau(\sigma)}} ;$

for

$\frac{M_{f} \delta}{2} \gg \Delta t$

it is

$c_{\tau} \doteq \frac{M_{E} \delta}{2}=\frac{M_{E}}{2 \nu}=\frac{N_{f}}{\nu}$

Where $\nu$ is the frequency and $\mathrm{N}_{f}$ the number of cycles at failure. Combining the last three equations and assuming the boundary case

$\left|\int_{\sigma, \sigma_{\max }}^{\sigma} \frac{d \sigma}{\tau(\sigma)}\right| \succsim \int_{\sigma_{0}}^{\sigma \max } \frac{d \sigma}{\tau(\sigma)}$

It follows that for $v \gg 1$ the residuum in Eq $(2.1 .4)$ can be neglected. Thus finally we obtain 
$\int_{\sigma}^{\sigma \max } \frac{d \sigma}{\tau(\sigma)}=\frac{b_{1}}{N_{f}}$, for $v>>1$

Inserting into Eq (2.1.10) the Eq (2.1.2) together with

$\mathrm{b}_{1}=2 \vee\left(\sigma_{\max }-\sigma_{0}\right)$

and solving for $N_{f}=\frac{M_{f}}{2}$ it is

$N_{f}=\frac{\nu \tau_{0}(a-1)(n+1)}{a^{(n+1)}-1}, \quad a \neq 1$

where

$a=\frac{\sigma_{\max }}{\sigma_{0}}$

The time to failure follows from $\mathrm{Eq}(2.1 .8)$ and $\mathrm{Eq}(2.1 .12)$

$c_{\tau}=\frac{\tau_{0}(a-1)(n+1)}{a^{(n+1)}-1}$; for $\nu>1$ and $a \neq 1$

It is easily shown that Eq (2.1.13) obeyes the model condition

$\lim _{a \rightarrow 1} c_{\tau}=\tau_{0}$

Combining this with Eq (2.1.8) it follows that

$\nu \lim _{a \rightarrow 1} C_{\tau}=\lim _{a \rightarrow 1} N_{f}=\nu \tau 。$

In Fig. 2 several $M_{f}(a)$-curves are calculated using values for Zircaloy -4 [2].

The conditon for neglecting the residuum in Eq (2.1.4), that is 


$$
\frac{1}{\left|b_{1}\right|} \int_{\sigma_{0}, \sigma_{\max }}^{\sigma_{f}} \frac{d \sigma}{\tau\left(\sigma^{\circ}\right)} \ll 1
$$

follows by combination of the above equation with the Eqs (2.1.9) $(2.1 .11)$ and the solution of the integral

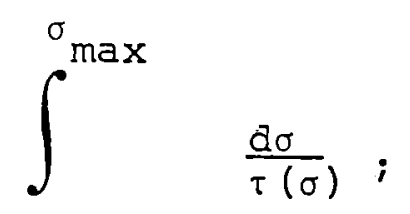

o

one obtains that

$\nu>\frac{a^{(n+1)}-1}{\tau_{0}(a-1)(n+1)} \stackrel{a^{n+1}}{\tau_{0}(a-1)(n+1)}$

\subsubsection{The Equivalent Stress $\sigma_{\mathrm{EQ}}$}

We define the equivalent stress as the static stress $\sigma_{E Q}$ for which the corresponding life time $\tau$ equals to the life time ${ }^{C_{\tau}}$ in a stress cycling experiment.

Thus for a given a-value the condition

$\tau=c_{\tau}$

is obeyed for

$\tau=\tau_{\circ}\left(\frac{\sigma_{0}}{\sigma_{E Q}}\right)^{n}$

Combining both these equations with Eq (2.2.13) we obtain $\frac{\sigma_{E Q}}{\sigma_{0}}=\left[\frac{a^{(n+1)}-1}{(a-1)(n+1)}\right]^{1 / n}$ $(2 \cdot 1 \cdot 1 \cdot 1)$ 
The condition inherent to the model is

$\frac{E_{Q}}{\sigma_{0}}<a$, for $a>1$

and

$\lim _{a \rightarrow 1} \frac{\sigma_{E Q}}{\sigma_{0}}=a$

For a particular case $\sigma_{E Q} / \sigma_{\circ}$ is plotted as a function of a in

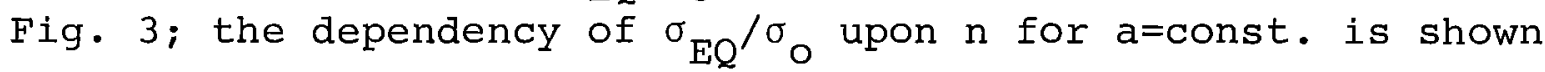
in Fig. 4 .

\subsection{Saw tooth stress-time profile with finite holding period}

The loading pattern for the case to be treated is shown in Fig. 5 . There is one holding period per loading step. The life fraction for one cycle is

$$
2\left[\frac{1}{b_{1}} \int_{\sigma}^{\sigma} \frac{d \sigma}{\tau(\sigma)}+\frac{t_{H}}{2} \frac{\tau_{\max }+\tau_{0}}{\tau_{0} \cdot \tau_{\max }}\right] \text {, }
$$

where $t_{H}$ is the holding time and $\tau_{\max }$ the life time at the constant stress $\sigma_{\max }$. Assuming the validity of the LFR it is

$M_{f, H}\left[\int_{\sigma}^{\sigma} \frac{d \sigma}{\tau(\sigma)}+\frac{b_{1} t_{H}}{2} \frac{\tau_{\max ^{+\tau}}}{\tau_{\max } \tau_{0}}\right]=b_{1}(1+R)$.

$M_{f, H}$ is the number of loading steps at fracture, $R$ denotes the residuum of the serie.

Inserting $\mathrm{Eq}(2.1 .2)$ into $\mathrm{Eq}(2.2 .1)$

for $\mathrm{R} \ll 1$ and $\mathrm{a} \neq 1$ the life time follows as

$$
c_{\tau_{H}}=\frac{M_{f, H}}{2 \nu}=\frac{N_{f, H}}{\nu}=\frac{1}{\frac{a^{n+1}-1}{\tau_{0}(n+1)(a-1)}+t_{H} \nu \frac{\tau_{\max }{ }^{+\tau_{0}}}{\tau_{\max } \cdot \tau_{0}}} ;(2.2 .2 \mathrm{a})
$$


if $\mathrm{n}>1$ and $\tau_{0}>\tau_{\max }$ it is approximately

$$
c_{\tau_{H}}=\frac{1}{\frac{a}{\tau_{0}(n+1)(a-1)}+\frac{t_{H}{ }^{\nu}}{\tau_{\max }}}
$$

As required by the model it is for $t_{H}=0$

$c_{\tau_{H}}=c_{\tau}$

In Fig. 6 the influence of $t_{H}$ upon ${ }^{c} \tau_{H}$ is shown for some particular cases.

Assuming $\tau_{\max } \ll \tau_{0}$ the condition $R \ll 1$ is obeyed if

$$
v_{H} \equiv \nu>>\frac{a^{(n+1)}-1}{\tau_{0}(n+1)(a-1) 1-\frac{t_{H}}{\tau} \max }
$$

Comparing Eq (2.2.3) with Eq (2.1.16) Eq (2.2.3) can be replaced by

$$
\nu_{H} \gg \frac{v}{1-t_{H} \tau_{\max }}
$$

For $t_{H} \ll \tau_{\max }$ this condition reduces to the condition defined by Eq $(2.1 .16)$ for the saw-tooth stress profile with zero holding time.

\section{Experimental}

In Fig. 7 the preliminary results from a serie of systematic investigations are shown for tensile stress cycling of a stainless steel of the type DIN 1.4970 .

The deformation was carried out with sheet type specimens in an 
"INSTRON" machine at $700^{\circ} \mathrm{C}$ in air atmosphere. Prior to sample machining the solution annealed material was $16 \%$ cold worked and finally annealed at $800^{\circ} \mathrm{C}$ for 2 hours. The static stress rupture behavior of this material has been extensively examined [4]. Therefrom the following values were used for stress cycling at $\mathrm{T}=700^{\circ} \mathrm{C}$

$\tau_{0}=2,2 \times 10^{7} \mathrm{sec}$ (corresponds to $\sigma_{0}=171 \mathrm{MPA}$ )

$\mathrm{n}=14$

In the experiments the lower stress limit $\sigma_{0}$ was kept constant. The highest $\sigma_{\max }-$ value was 0,97 (UTS) at $700^{\circ} \mathrm{C}$.

As one can realize from Fig. 8 the agreement between experimental values and those calculated from Eq (2.1.12) is for $\mathrm{N}_{f}$-values below $\approx 10^{3}$ fairly good. The systematic deviation for higher $\mathrm{N}_{\mathrm{f}}$-values is probably due to a change in the microstructure of the material. For this type of steel it is reported [4] that precipitation occurs on grain boundaries when the material is subjected to long time creep.

\section{Acknowledgement}

The author is indebted to $\mathrm{Mr}$. Schäfer for leaving the experimental results for evaluation prior to publication. 


\section{Literature}

[1] S. Taira: "Creep in Structures", Springer,

Berlin-Göttingen-Heidelberg, 1962 , p. 96.

[2] M. Boček: Creep rupture at non-steady stress and temperature loading conditions, KfK 2699, November 1978

[3] B. Ilschner: "Hochtemperaturplastizität", Springer, Berlin-Heidelberg-New York, 1973

[4] M. Schirra: Einfluß mechanisch-thermischer Vorbehandlung auf das Zeitstand- und Kriechverhalten des Strahles x 10 NiCrMoTiB 1515. KfK 1535, Januar 1972 


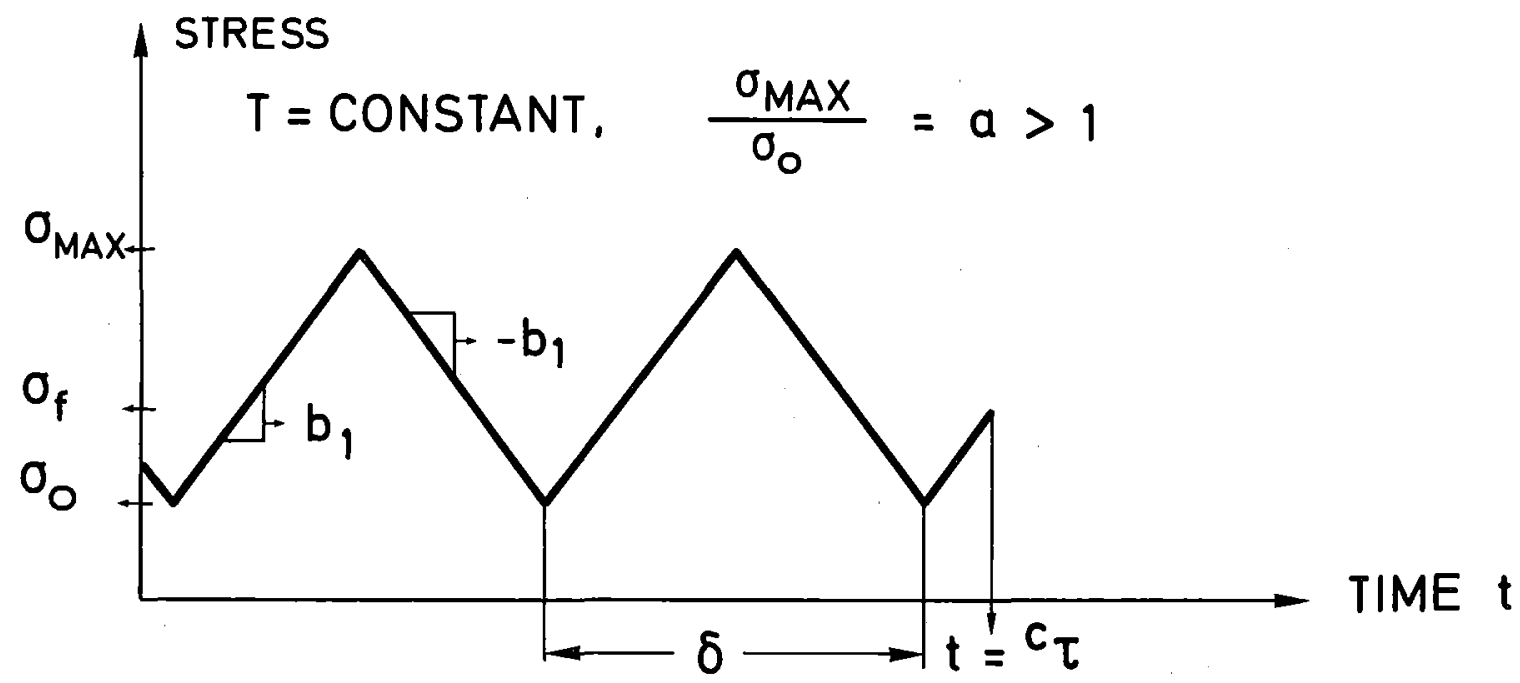

$b_{1}=2 \vee \sigma_{0}(a-1)$ STRESS RATE

$M_{f}$ NUMBER OF HALF - CYCLES TO FRACTURE

$c_{\tau}$ TIME TO FRACTURE

$\delta$ PERIOD; $\frac{1}{\delta}=V$ FREQUENCY

$N_{f}=M_{f / 2}={ }^{c} \tau \vee$ NUMBER OF CYCLES TO FRACTURE

Fig. 1 The stress-time function. 


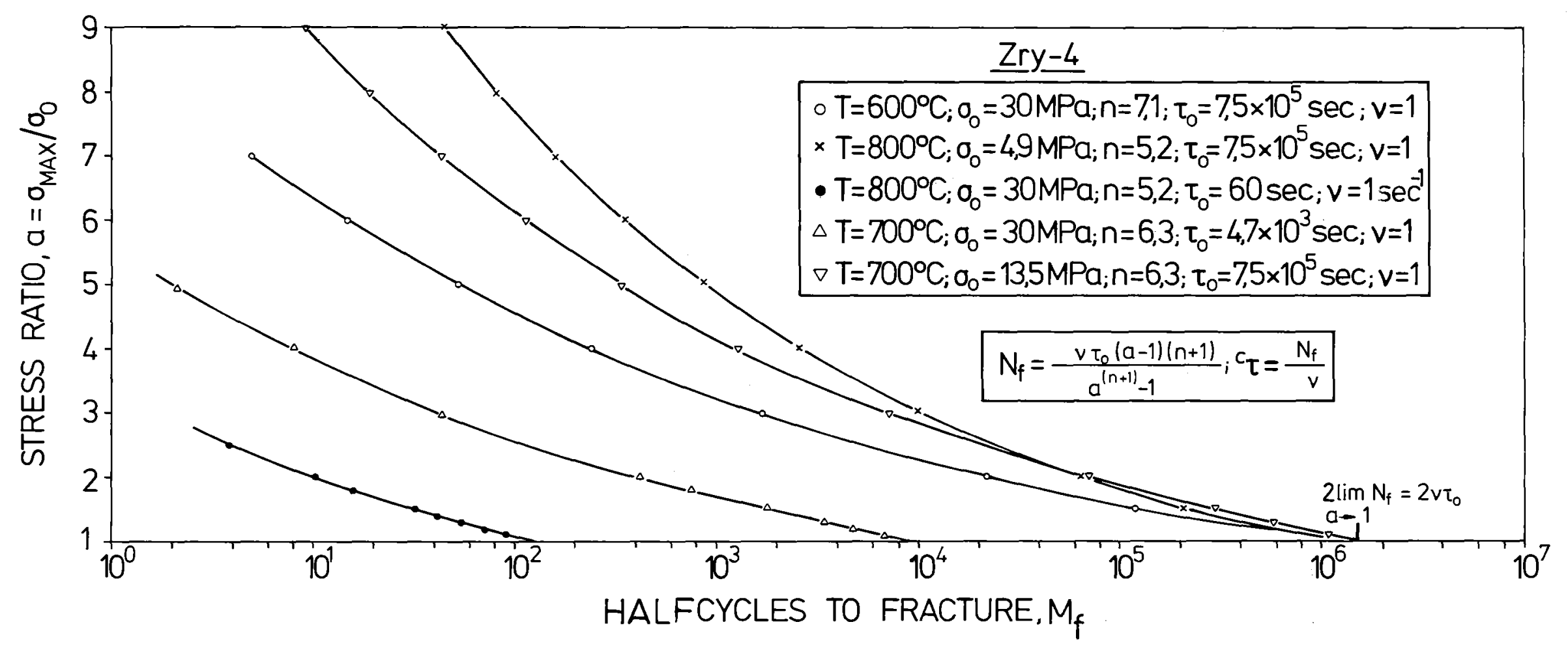

Fig. 2 Number of halfcycle at failure vers. ${ }^{\sigma} \max / \sigma_{\circ}$. 


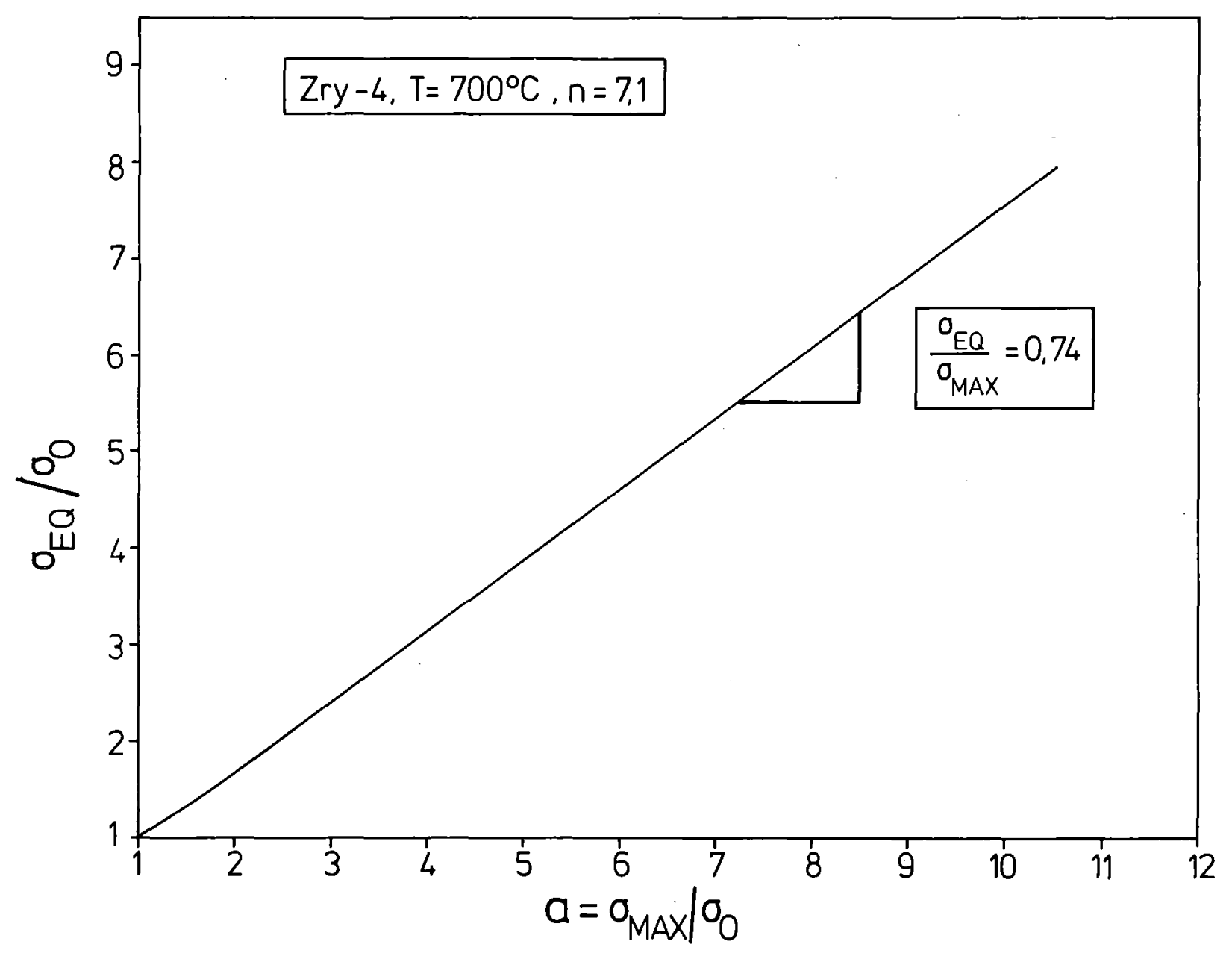

Fig. 3 The dependence of $\sigma_{E Q}$ upon $\sigma_{\max }$ • 


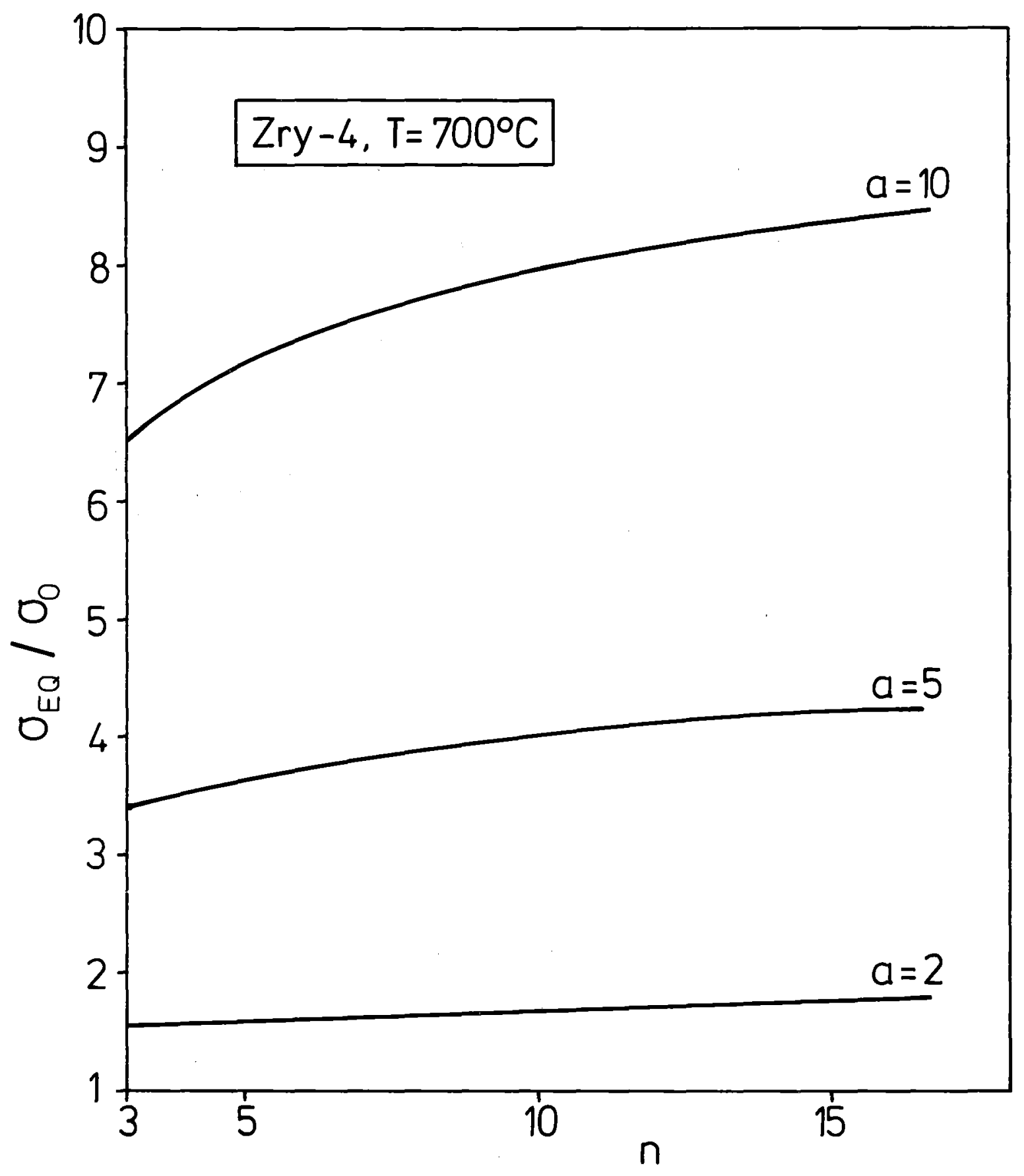

Fig. 4 The stress ratio $\sigma_{\mathrm{EQ} / \sigma_{\mathrm{O}}}$ as a function of $\mathrm{n}$. 


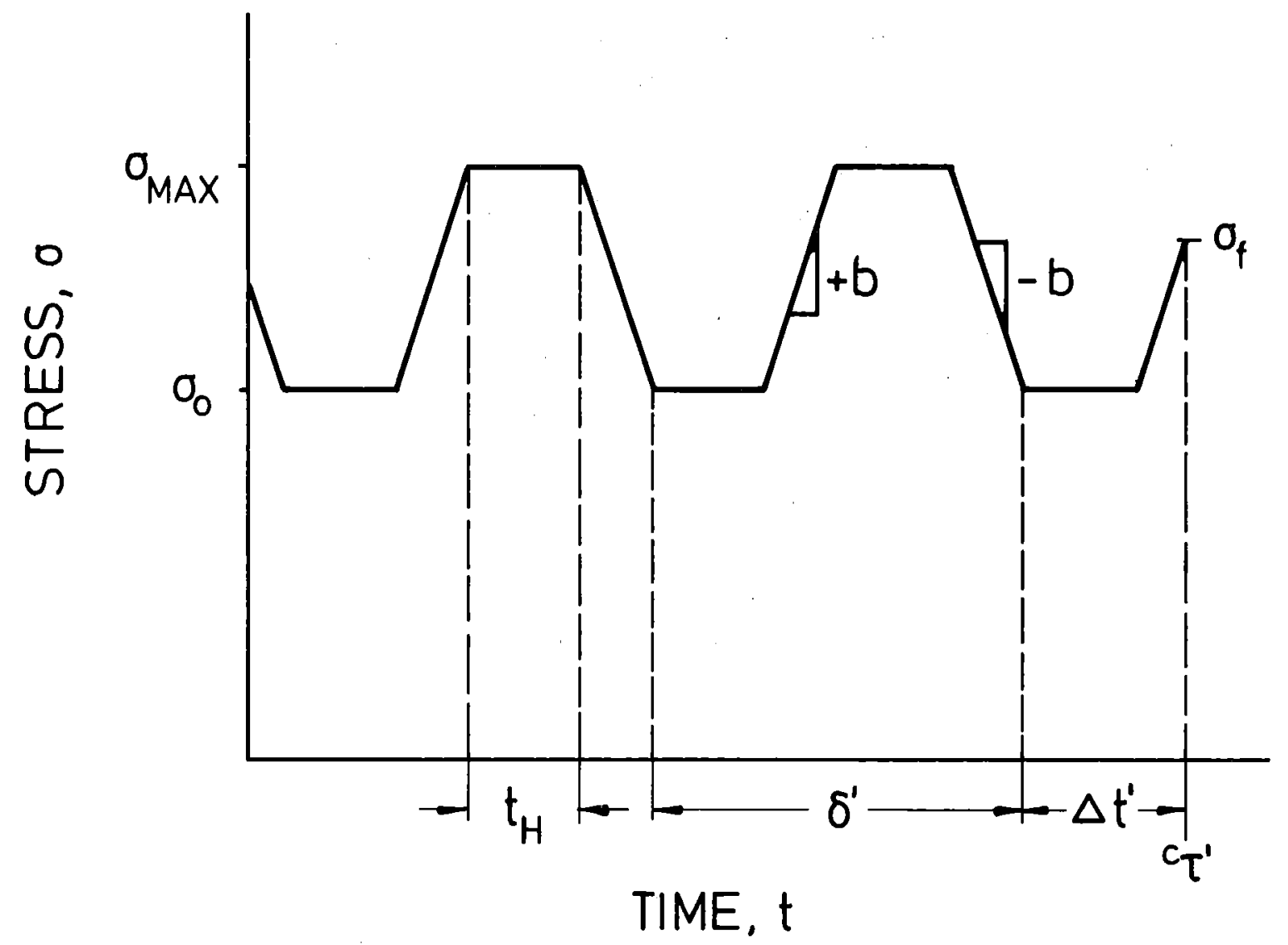

Fig. 5 The stress-time function with holding period. 


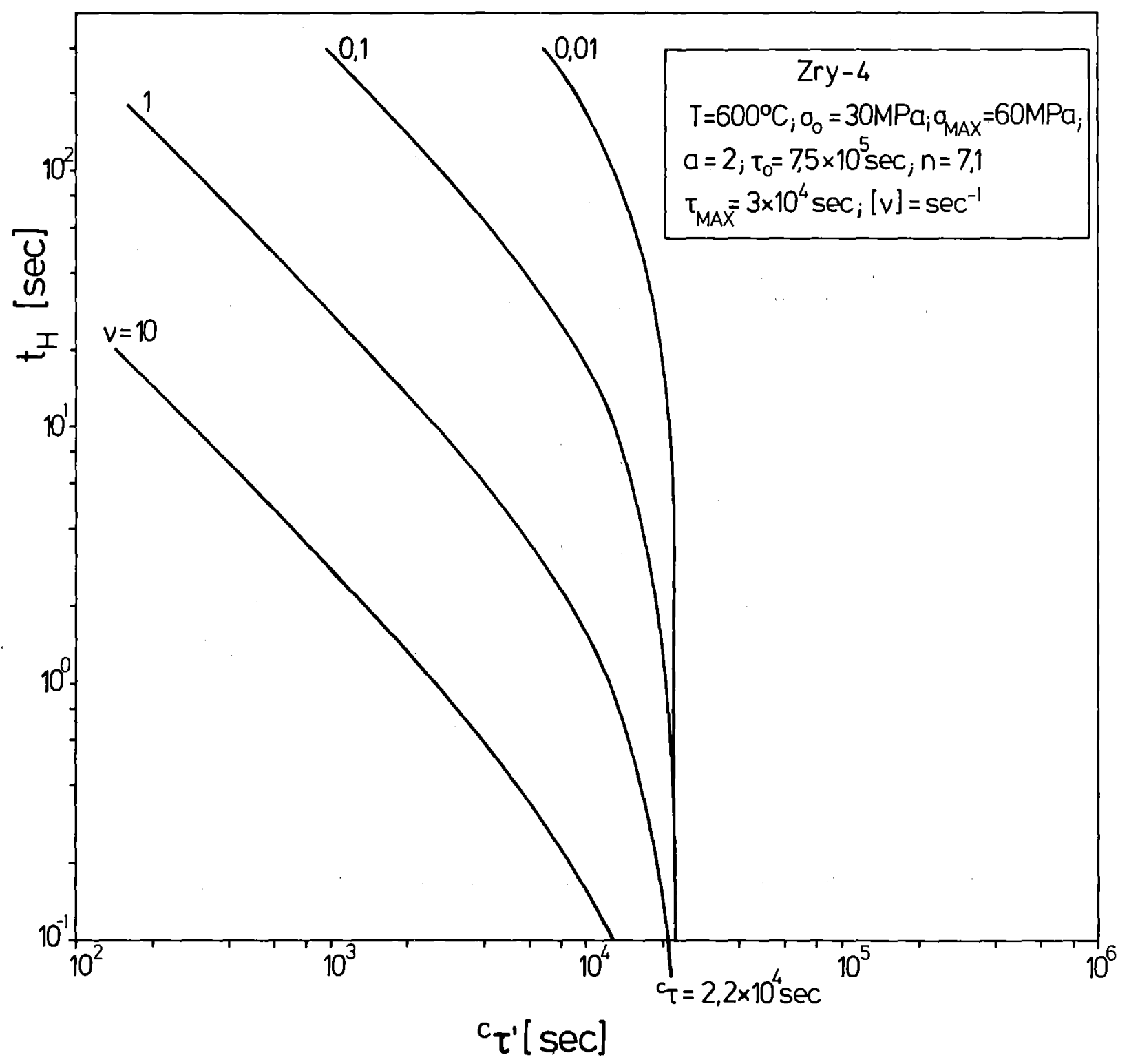

Fig. 6 The dependency of the life time upon the holding time. 


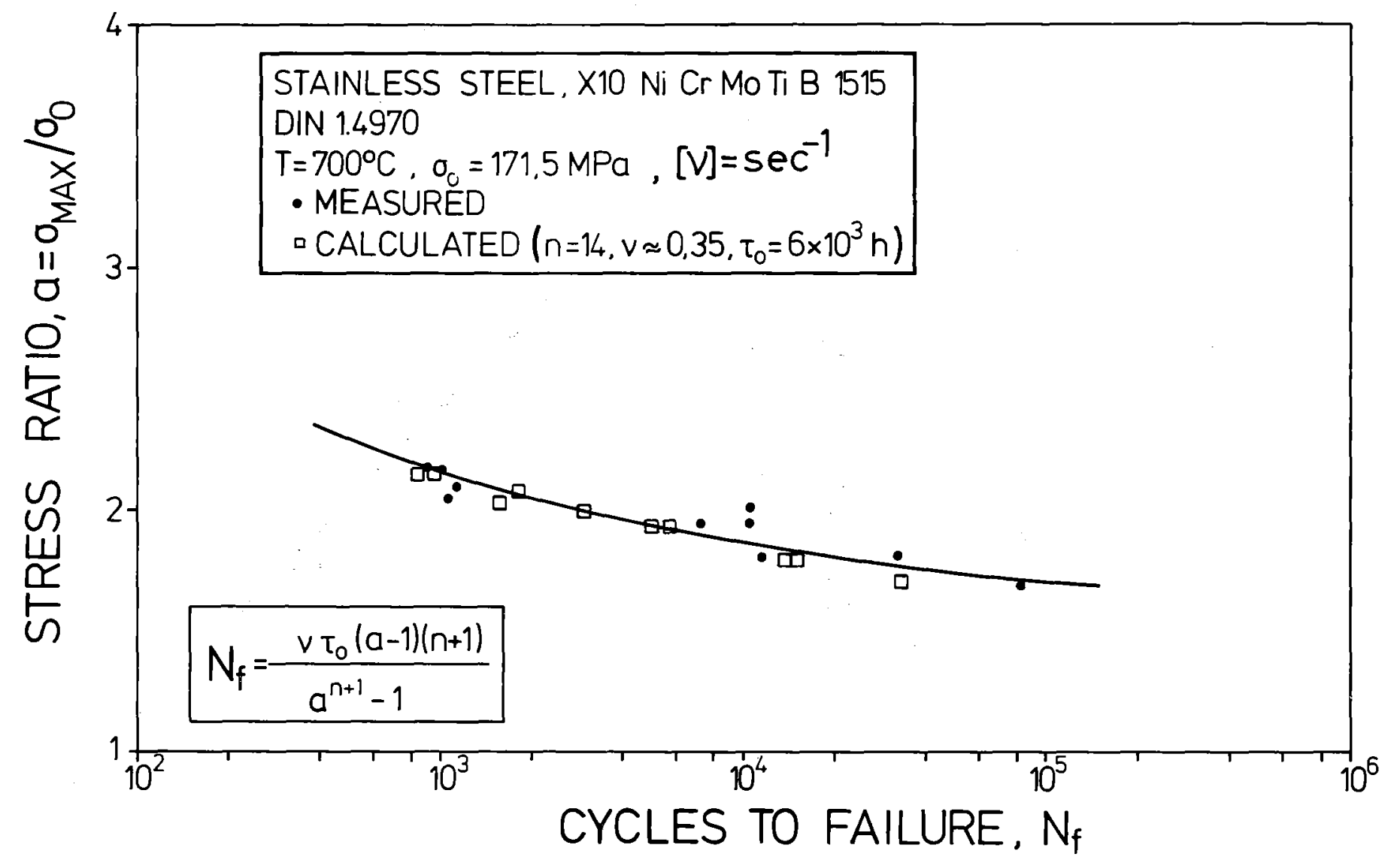

Fig. 7 An experimental $\mathrm{N}_{f}(\mathrm{a})$-curve. 


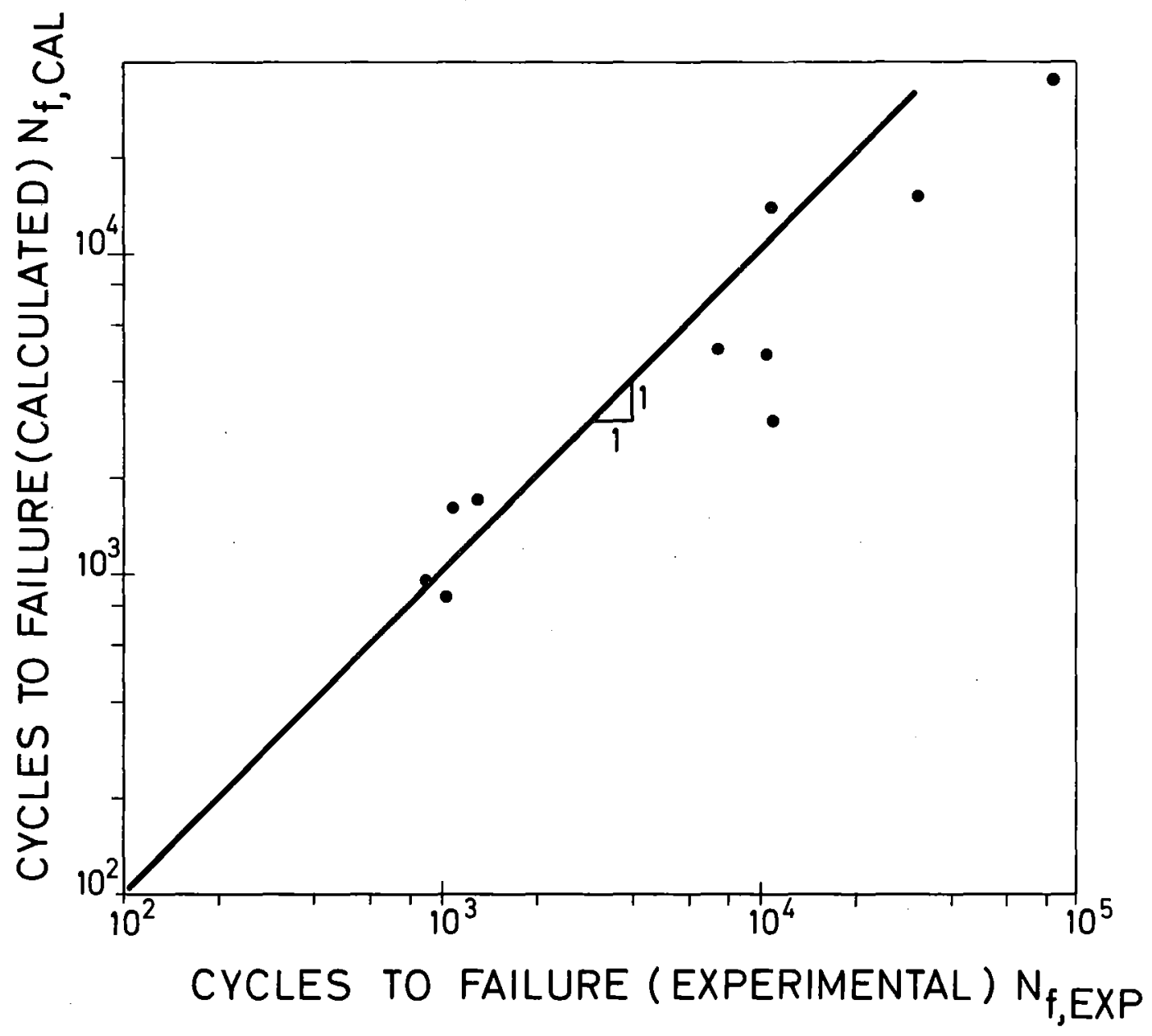

Fig. 8 Comparison of the measured $\mathrm{N}_{f}$-values with calculated ones. 